\title{
ON HEALTH DEVIATION AND REHABILITATION IN SPINAL PARAPLEGIA AND TETRAPLEGIA*
}

\author{
Professor Sir Ludwig Guttmann, C.B.E., F.R.S., M.D., F.R.C.P., F.R.C.S. \\ Emeritus Consultant to the National Spinal Injuries Centre, \\ Stoke Mandeville Hospital. Founder and former Director of the Centre, \\ Aylesbury, Bucks.
}

THIs lecture, which I am greatly honoured to deliver today, is to honour the memory of Sir Henry Harben, one of the outstanding philanthropists of the last century and the early years of the present one. Sir Henry, born in I823, died in I9I I at the age of 88. During his long life, he witnessed great advances and discoveries in medicine and social welfare, which were fundamental contributions to the treatment of hitherto incurable diseases and curses of mankind, resulting in steady development of preventive medicine and public health. Some of Sir Henry's numerous benefactions were the foundation of a life insurance scheme for the working classes, the setting up of a convalescent home in Rustington, the building of a wing at the Hampstead General Hospital, his support for Mount Vernon Hospital for tuberculous patients, and the building of a school for the blind.

My task today is to talk on Health Deviation and Rehabilitation in Spinal Paraplegia and Tetraplegia, a subject of medicine which, in Sir Henry's lifetime, was one without hope, as it was indeed for many centuries before and-alas-is still today in certain countries.

\section{Definition}

In defining and analysing health deviation and rehabilitation of sufferers from severe injury of the spinal cord, one of the greatest tragedies in human life, one has first to distinguish health deviation in the immediate and early stages as well as later stages, once the paralysed has left the haven of hospital life and is confronted with the world around him. Secondly, one has to consider health deviation occurring in various age-groups affected by paraplegia and tetraplegia-childhood, adolescence, prime of life and old age. Some difficulty arises in the definition of 'prime of life', and there are different opinions in this respect. Obviously, it depends from which aspect prime of life is considered. For instance, the prime of life of a professional boxer or rugby or soccer player is quite different from that of other professions, such as scientists, doctors, lawyers, teachers, and businessmen. Age-groups considered as prime of life vary from $25-35,25-40,30-55$ and even 30-60 years of age. Some people - amongst them late developers-hold the view that prime of life is not restricted to a certain age, so long as one is in full possession of one's mental and physical qualities and able to carry out professional and social activities with an ability to enjoy life. Be this as it may, for the purpose of this lecture my somewhat arbitrary assessment of prime of life includes people between 25 and 48 years of age, as, generally speaking, these are individuals who have finished their training or

* The Harben Lecture, Royal Institute of Public Health and Hygiene, 1976. Reprinted with permission from Community Health 8, 186-208. 
higher education, are settled in their jobs or professions, living a full family and social life, and are on the way to their peak or have even reached it.

The third aspect to be considered in health deviation of severely disabled, such as spinal paraplegics and tetraplegics, is the personality problem of the individual, and their reaction to their disability, especially of those in the prime of life. For, the physical defect affects not only healthy individuals of varying normal mental make-ups, temperaments, intelligence and education, but also psychopathic personalities.

\section{Health Deviation in the Acute and Early Stages of Paraplegia and Tetraplegia}

A transection or severe injury of the spinal cord, be it caused by fracture or dislocation of the vertebral column, gunshot or stab injury or by acute inflammation or vascular process of the spinal cord, is not just an acute illness with temporary health deviation. It has staggering immediate as well as long-term effects on the body without a controlling system. For the spinal cord is not only the main mediator of all impulses to and from the brain but in addition it represents an important centre of nerve supply in its own right. Therefore, such an injury deprives the individual in the nick of a second not only of one but of a multitude of essential functions of the whole organism. He has lost all voluntary movements and all forms of sensation below the level of the injury, and the higher the site of the cord damage the greater the number of motor and sensory functions cut off, resulting in postural hypotension and fainting in the higher lesions when the patient is raised from the horizontal to the vertical position (Guttmann, 1946: Guttmann et al., I963) (Fig. I). In injuries of the cervical cord, the main respiratory muscles are paralysed, resulting in immediate severe impairment of breathing and reduced vital capacity of the lung of values as low as 0.3 and even 0.1 litres. Moreover, the individual has lost control of bladder, intestinal and sexual functions. The paralysis of the intestinal function may result in paralytic ileus followed by meteorism which, in turn, may add to the pulmonary distress as the result of interference with the functions of the main respiratory muscle, the diaphragm (Guttmann, I973). Furthermore, in transection of the cord above the 6th thoracic segment, the blood circulation is greatly interfered with in the initial stages of injury, as a result of the interruption of the vasoconstrictors which descend from the mid-brain and travel within the spinal cord, resulting in disturbance of the vaso-motor control, and consequently disturbance of temperature regulation, and also to development of venous thrombosis and lung embolism which may endanger the life of the individual within the first days or weeks after injury. The disturbance of temperature regulation is particularly conspicuous in cervical cord injuries (Guttmann et al., I958; Johnson and Spalding, I964).

It is obvious that if the body is thrown into chaos by such a multitude of physical alterations the soul must follow and the psychological structure of the individual becomes disorganised. In the immediate stage of spinal paralysis, the patient as a rule is dazed and clear thinking is retarded. It may take some time before the paralysed is able to register the extent of his severe disablement. In tetraplegic patients, anoxia, the oxygen deficiency of the brain resulting from the paralysis of the respiratory muscles, may lead to a confusional state, also in paraplegics if the spinal cord injury is associated with some cerebral concussion, and loss of consciousness or a confusional state may last a considerable time. However, once the initial stage has subsided and the spinal paralysed becomes fully aware of his bodily 

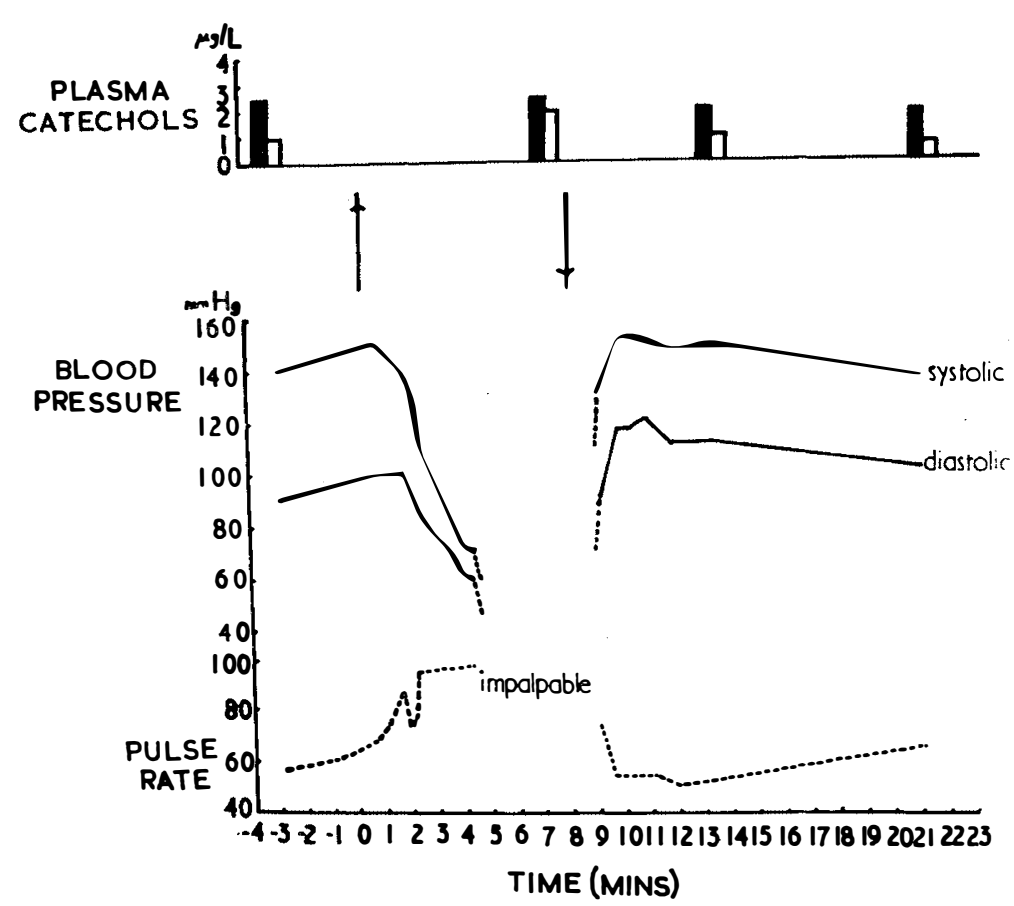

FIG. I

Effect of tilting from the horizontal to the vertical position in a case of cervical injury below C. 6 .

plight and his profound physical limitations and their implications for his future life, then a reactive depression and a number of anxieties and other reactive mental disorders, such as denial, regression, self-deception, etc. become manifest. Some of these are identical with those of other severely disabled persons, such as blind and double amputees, namely fear of chronic crippledom with all its restrictions of social activities and economic consequences, resulting in loss of earning capacity, and of becoming a burden to the family and everybody else. There are, however, additional anxieties of specific nature associated with paraplegia in connection with loss of control of bladder, bowels and sexual functions. No doubt, the loss of sexual function constitutes a severe psychological shock to most male paraplegics as well as tetraplegics, the more so as the urge for the other sex, the libido, remains intact. To many patients, all these anxieties are at first overwhelming and in some patients may set up negativistic attitudes associated with a sense of resentment against their fate and society. In others, they may result in self-pity and self-centredness as a result of frustration. In this frame of mind the patient may revert to childhood by leaning on the doctor, nurses and physiotherapists, as he did as a child on his mother, and he is quite content with the various passive measures of treatment, having lost activity of mind and self-confidence. Although this stage of regression or denial can be overcome in the great majority of patients in the early stages of rehabilitation, by empathy on the one hand and firm handling on the other on the part of the medical and paramedical staff, there are certain psychopathic individuals who will develop excessive emotional reactions such as outbursts of excessive irritability and displays of temper. 


\section{Secondary Physical Health Deviation}

Already in the immediate and early stages following spinal cord injury, complications not infrequently occur, if the initial management is inadequate. These are secondary health deviations as the result of the cord injury. Mention has already been made of the danger of venous thrombosis and embolism and in tetraplegia ileus and lung complications including those following tracheostomy such as airway obstruction, pressure of the trachea leading to stricture and tracheal stenosis, etc.

However, the two complications which are mainly responsible for early death and chronic invalidism are infection of the paralysed bladder ascending into the upper urinary tract and eventually leading to destruction of the kidneys on the one hand, and pressure sores resulting in osteomyelitis and septic absorption on the other. These complications which develop as a rule in the early weeks and months after injury, as the result of inadequate management, were considered throughout the centuries as inevitable and consequently led to the widespread defeatist attitude on the part of the medical and paramedical professions all over the world. The general view held was that nothing or little could be done for these unfortunate people and the sooner they died the better for all concerned. This hopeless frame of mind, held even by experts, has been vividly expressed in the literature (Wagner and Stolper, 1898; Cushing, 1927; Gowland, I94I; Dick, 1949). Consequently, the mortality rate of traumatic paraplegics was always very high, and in the American and British Armies in the First World War it was 80 per cent within the early weeks or months following injury. The few survivors lived their lives as useless and hopeless cripples, unemployable and unwanted, and were doomed to spend the rest of their lives at home or in institutions for incurables, with no encouragement to return to a useful life. Actually, the then existing legislation and regulations regarding war pensions and workmen's compensation made it quite impossible for these 100 per cent disabled men to return to remunerative employment for fear of losing their pensions and compensation. In the interwar period, this defeatist attitude of most members of the medical profession in this and other countries was still prevalent. The general despondency is revealed in the report of the Medical Research Council of 1924: 'The paraplegic patient may live for a few years in a state of more or less ill health'. Even during the Second World War, this view was widely held, and it was significant that in all discussions on rehabilitation during the years 1939-42, the subject of rehabilitation for victims of spinal paraplegia (let alone tetraplegia) was hardly ever mentioned, in spite of the fact that the modern principles of rehabilitation had been successfully applied to other forms of disablement.

\section{Rehabilitation: Early Spinal Units-Fragmentation of Management}

A fundamental step forwards in a new approach to the problem of management of spinal cord sufferers was taken first in Great Britain during the Second World War by the Peripheral Nerve Committee of the Medical Research Council under the leadership of the late Dr George Riddoch, a leading neurologist and adviser to the British Army and the Ministries of Health and Pensions. It was decided to congregate spinal cord casualties in special spinal injury units within the EMS and Ministry of Pensions hospitals in Great Britain, for it was anticipated that the number of war casualties with spinal cord injuries would be considerably increased by air raid casualties among civilians. There were several reasons for this decision: 
It was generally agreed that conditions for a systematic study of the many aspects concerned with the treatment and rehabilitation of these patients and specialised treatment were infinitely more favourable in spinal units than if these cases were scattered in general medical or surgical wards, from which as a rule they were transferred to chronic wards or homes for incurables. Although it was assumed that with the development of specialties such as neurology, neurosurgery, orthopaedic surgery, urology and other specialties, these patients could be better managed by these specialties, this concept only led to a fragmentation of treatment which in due course proved quite unsatisfactory, as the facilities available were limited to the study of specialised problems and short-term treatment only. Above all, these departments were so busy with their many other afflictions in their specialties that as a rule it was quite impossible for both the medical and the nursing staff to give paraplegics and tetraplegics that meticulous care and attention which these patients need day and night, especially during the acute and early stages. Therefore, after the specialised treatment was finalised, these patients were, as a rule, still transferred to wards or institutions for chronics and incurables or sent home without hope for returning to the community as useful members.

During the course of the war, ten spinal units were gradually set up in various parts of the country. However, in those days it was not generally recognised by either the medical or the administrative authorities that in order to prevent these spinal units becoming merely an accumulation of doomed cripples, the provision of certain arrangements was indispensable:

I. Most important of all, supervision of such a unit by an experienced physician or surgeon, who was prepared to give up some of his own specialty in order to devote his lifetime work to this multidisciplinary specialty of medicine and surgery which demands meticulous attention to detail, to plan and organise those many details of treatment and, lastly but by no means least, to correlate the sometimes conflicting interests of visiting medical and surgical specialists concerned with special aspects of the management.

2. Nursing and other paramedical staff such as physiotherapists and occupational therapists sufficient in number to cope with the many details involved in the work, in particular avoidance of the usual practice of changing the nursing staff from one department to another at short intervals.

3. Adequate technical facilities such as workshops for social rehabilitation and pre-vocational training.

4. Arrangements for domestic and industrial resettlement.

5. After-care by regular check-ups of patients discharged from hospital.

6. Facilities for research, for this multidisciplinary subject of spinal paraplegia as well as tetraplegia with their multitude of health deviations offered enormous opportunities for systematic research on a great variety of physiological, biochemical, clinical, psychological and pathological problems.

It was, therefore, not surprising that these early spinal units did not prove satisfactory; indeed no great encouragement was given to those medical men who were charged with the task to run them. T. B. Dick (1949) has given a vivid account of the unsatisfactory conditions prevailing in the early years of the war in one of the first spinal units where some 40 cases were treated. Although a neurosurgical team was in charge of the spinal unit, he states: 'No one member of that team devoted more than a part of his time to the care of spinal injured cases. . . . It was not uncommon at this period on a ward round to find virtually every case of 
paraplegia with persistent pyrexia. ... There did not appear as yet to be any definite plan or end in view of the rehabilitation of even the very fit patients.'

\section{A New Approach}

It was in September 1943 that the Government decided to set up a new Spinal Unit at the Ministry of Pensions Hospital, Stoke Mandeville in Aylesbury, as one of the medical preparations for the planned Second Front offensive in spring 1944. With the opening of this Unit on I February 1944, a new era began for spinal cord sufferers when I introduced a concept of a comprehensive service for paraplegics and tetraplegics including all aspects of the initial as well as long-term treatment and rehabilitation. The chief object in this multidisciplinary subject of medicine was to establish a synthesis between all clinical procedures, whether medical or surgical, with all measures for vocational training as well as domestic and social resettlement of these patients to rescue them from the human scrapheap and to return most of them, in spite of their profound disability, to the community as useful and respected citizens. These various measures were not considered as separate entities, which hitherto constituted the fragmentation of management, but, a priori, and throughout all stages, as a common operation. In particular, rehabilitation was not considered as a third phase but as commencing on the day of injury. Naturally, the practical application of this philosophy was no simple task, in view of the centuries-old prejudices and negative attitudes towards paraplegia, let alone tetraplegia. Actually, in the first 2 years of our work, the question asked by many visitors with monotonous regularity was, 'Is it really worth while?' The reflection of this defeatist attitude of the public on the paralysed themselves was significantly expressed by one of my early patients, a wounded clergyman, who wrote in an essay on his own reaction to his paraplegia: 'One of the most difficult tasks for a paraplegic is to cheer up his visitors'!

Patients were admitted to the Spinal Centre at varying intervals after injury or onset of disease-and in many cases their condition was extremely serious. They can be conveniently divided into the following groups:

I. Patients admitted immediately or at an early date after injury. During the war they were admitted from First Aid Posts of the Normandy front or bombed cities, arriving often with gaping wounds caused by bullets or shell fragments, sometimes with discharging cerebral spinal fluid or with associated injuries to other organs. Since the war, when the great majority of traumatic cord injuries have been due to fractures or fracture dislocations caused by road or industrial accidents or as a result of sport accidents, in particular due to diving, rugby, trampoline, riding, climbing, vaulting-horse, etc., patients have been admitted in increasing numbers either immediately or within the first few days after injury from Casualty Departments or from Accident, Neurosurgical and Orthopaedic Units. This has been increasingly recognised by surgeons in this country as the most satisfactory procedure for avoiding early infection of the paralysed bladder and other complications.

2. Patients admitted at later stages. These patients came in with signs of septic absorption resulting from infection of the urinary tract, producing stones in bladder or kidneys, hydro-utereter with hydro- or pyonephrosis, or suffering from multiple pressure sores of various size and depth, producing osteomyelitis with destruction of joints. Many of this group showed signs of nutritional deficiency and some, especially during the early years of our work, showed extreme malnutrition comparable with that of inmates of concentration camps, and I called them the 'Belsen type' of paraplegia (Fig. 2). 


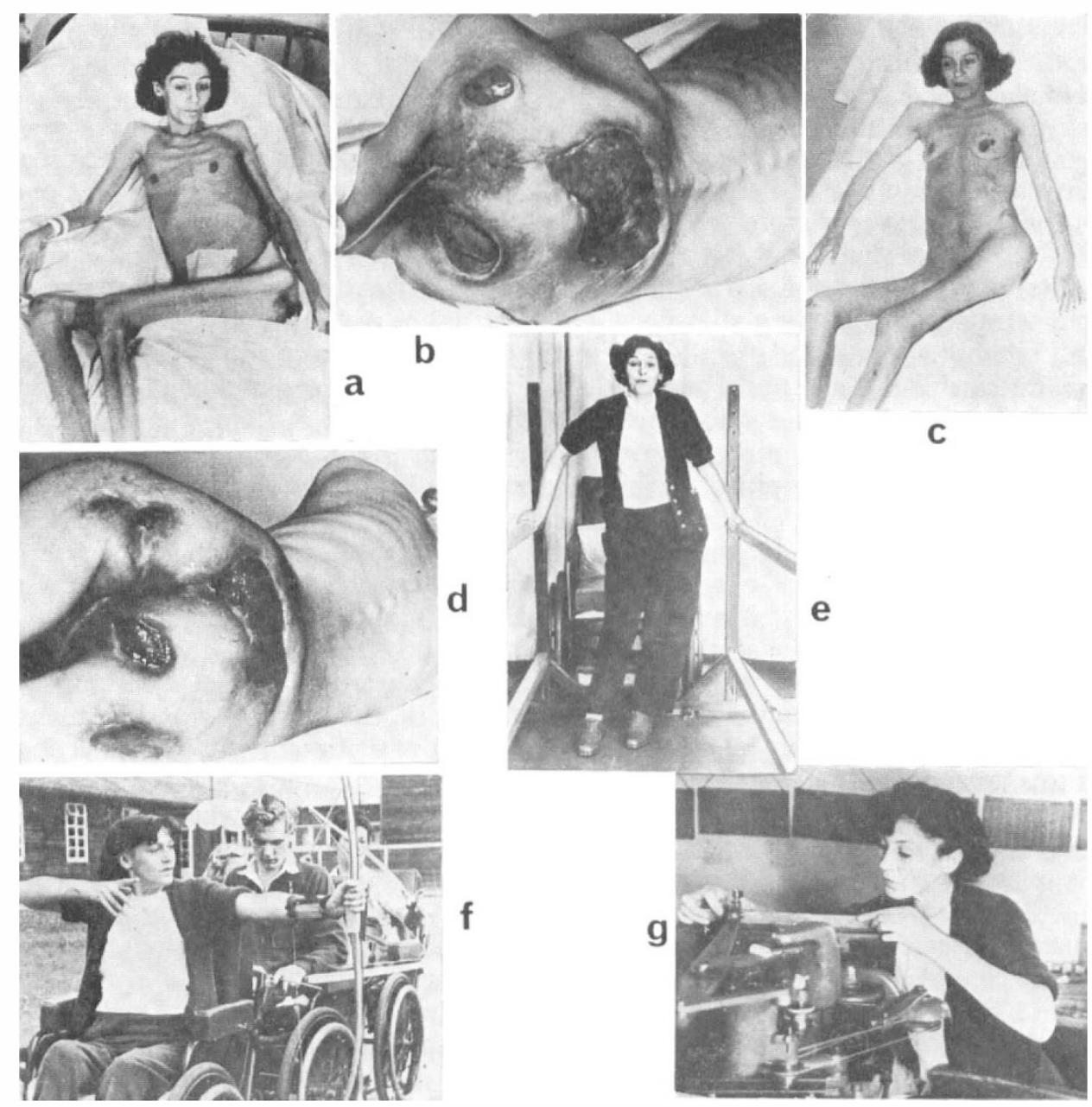

FIG. 2

Belsen type of paraplegia in incomplete lesion below $\mathrm{T}_{4}$ following stab injury. Stages of rehabilitation after admission to Stoke Mandeville. $(a),(b)$, On admission four months after injury. $(c),(d), \mathrm{I} \frac{1}{2}$ months after admission. $(e),(f),(g)$, Four months later.

Another group of late arrivals were patients where pain and intractable spasticity overlaid by contractures were in the foreground of the symptomatology through inadequate management and neglect (Fig. 3).

The third group of late arrivals were those with more or less satisfactory physical condition but who were demoralised and resigned into their disability as the result of enforced prolonged inactivity in hospitals, institutions or at home.

Last, but by no means least, were ex-patients of the Spinal Centre either discharged to their own homes, institutions or settlements, who were admitted for routine check ups or readmitted because of flare-ups of their urinary infection or other complications.

It is obvious that radical changes in the medical, surgical and psychological 


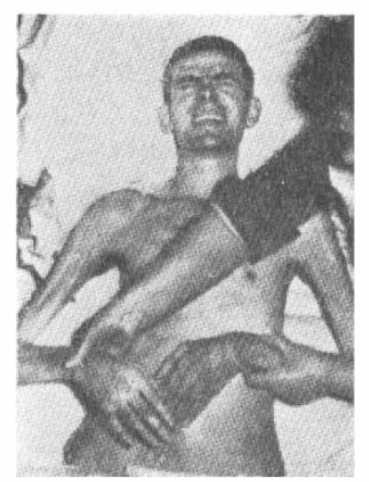

$a$

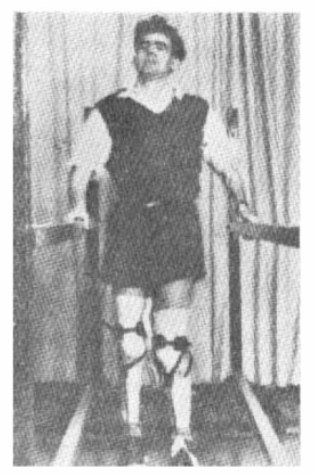

$c$

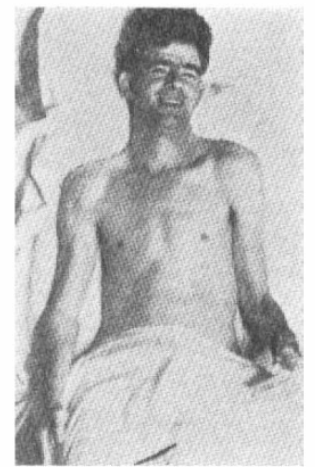

$b$

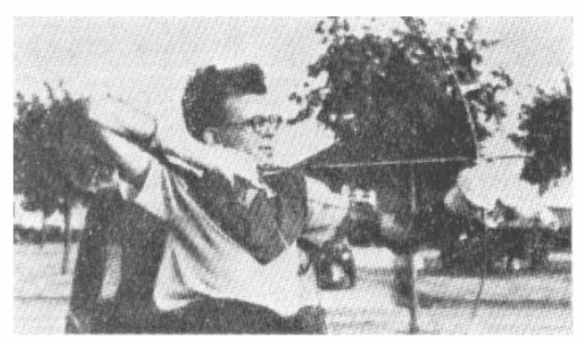

$d$

FIG. 3

Contractures of the elbow in an incomplete cervical injury due to inadequate initial treatment elsewhere. Stages of rehabilitation after admission to Stoke Mandeville.

approach to this very complex problem had to be introduced to overcome old traditions, dogmas and prejudice.

It was quite unorthodox in those days to reject the conventional method of recumbency and immobilisation of traumatic paraplegics in plaster casts and plaster beds, as well as to abstain from hasty and indiscriminate operative procedures, in particular laminectomy and open reduction by various stabilising methods with metal plates or springs or anterior or posterior fusions, as the initial treatment of the broken spine. They were replaced by new methods aimed at the utilisation and mobilisation of the natural forces of repair so inherent in the human organism. The method introduced in 1944 to deal with fractures of the vertebral column resulting in cord injuries was the method of gradual postural reduction on pillow or sorborubber packs and regular turning every 2 hours day and night. (Guttmann, I946a, $b$, I955, I973) (Fig. 4). In cervical injuries, skull traction sometimes combined with careful manipulations became the method of choice. In order to relieve the nursing staff from constant strain of lifting and regular turning of the patient day and night, an electrically-operated turning and tilting bed was eventually developed, in cooperation with members of my staff and a factory, known as the Egerton-Stoke Mandeville bed, in which I designed a special head traction unit for tetraplegics 


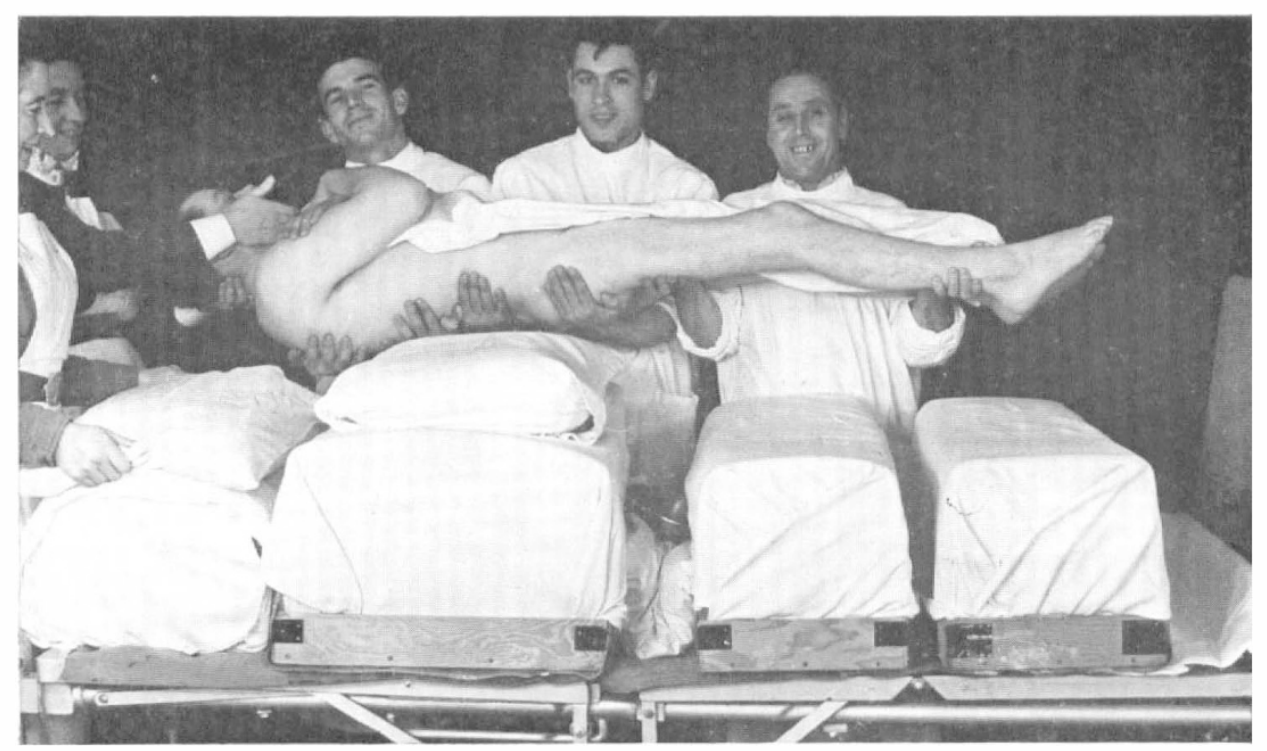

FIG. 4

Postural reduction of a patient with a fracture dislocation of the thoracic spine on sorborubber packs. Note the special cushion underneath the fracture promoting restoration of normal curvature of the spine.

which allowed turning the patient from the horizontal to $70^{\circ}$ lateral position without removing the weight for the skull traction (Figs 5,6). It was found that with these methods of postural reduction, even the most severe fracture dislocation could be reduced, whether antero- or retro-hyperflexion or rotation injury and associated with blocked facets, or whether stable or unstable fractures (Figs 7-II). It may be noted that in contrast to the publications of other authors, the incidence of late instability in a series of 612 fractures of various levels of the Stoke Mandeville team was found to be very low-0.65 per cent (Frankel et al., 1970).

It was also at that time a new approach for both medical and nursing staff to be taught that bed sores resulting in osteomyelitis and sepsis were by no means inevitable consequences of spinal paraplegia, as commonly accepted, but that these complications as well as others such as contractures and intractable spasticity could, by introducing new methods of management, be not only controlled but altogether prevented (Guttmann, 1945, I955, I973). Some types of pressures sores, contractures and intractable spasticity are illustrated in Figures I2-I4.

The continuous drainage of the paralysed bladder by immediate suprapubic cystotomy, which in the Second World War was considered by most surgeons as the method of choice for the initial treatment of the paralysed bladder, was rejected from a point of principle as unphysiological since it added local damage of the bladder wall to the neurogenic bladder. This method was replaced by the nontouch technique of intermittent urethral catheterisation carried out in the acute stages by the medical attendant himself and not, as was the custom, by nurses, let alone orderlies (Guttmann, 1949). It could be proved that suprapubic cystotomy did not prevent ascending infection as was erroneously believed; on the contrary, it often led to serious complications such as reflux-stone formations in bladder and 


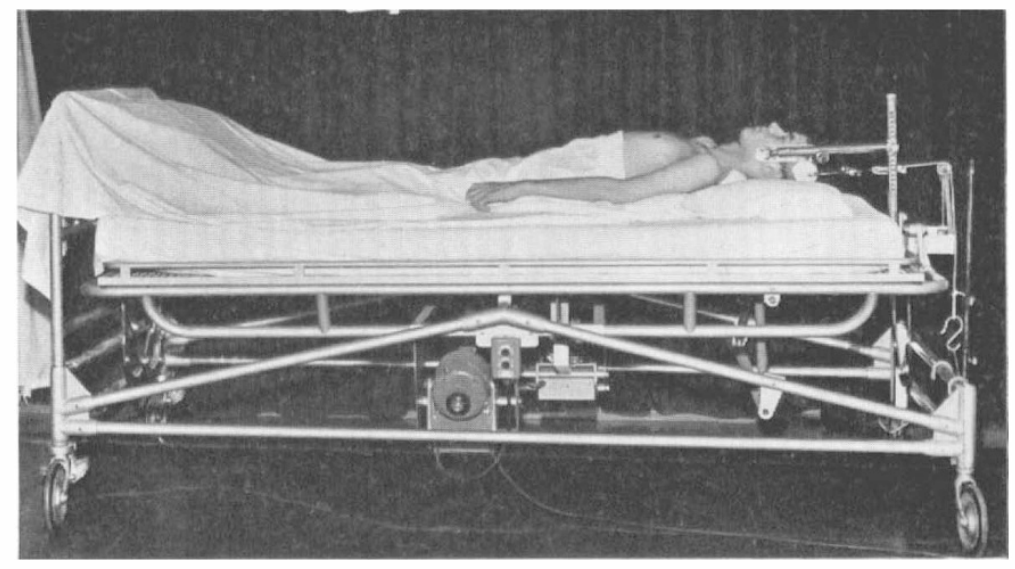

FIG. 5

Stoke Mandeville-Egerton electrically controlled turning and tilting bed.

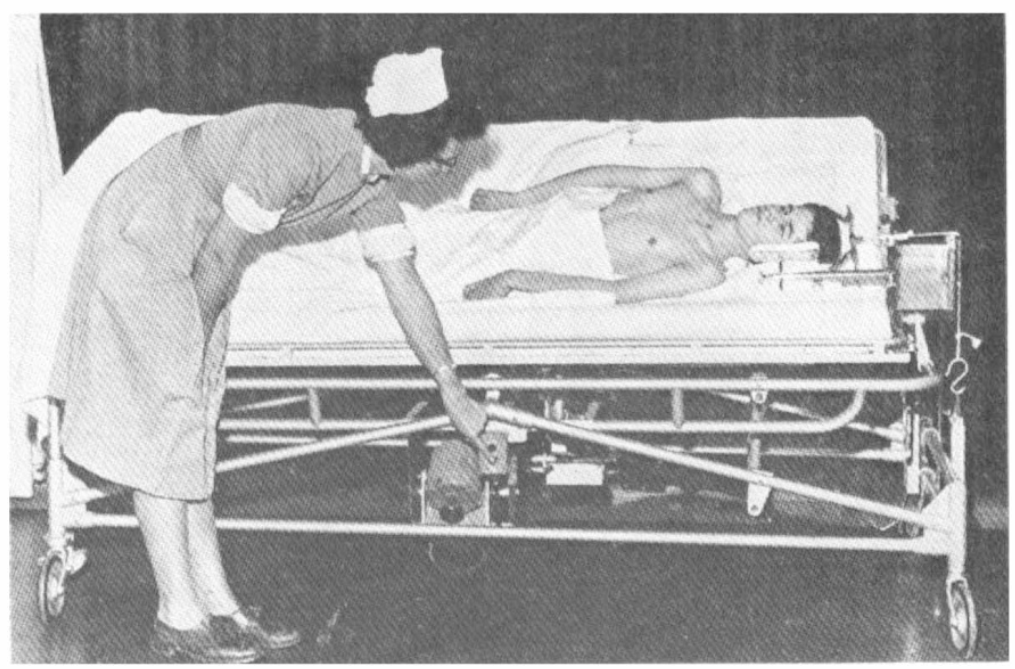

FIG. 6

Turning of a tetraplegic by pressing a button. Note the special head traction.

kidneys, contracture of the paralysed bladder resulting in adverse effects on the autonomic and in particular the cardiovascular system, as well as development of hydronephrosis or pyonephrosis (Guttmann, I953, I973) (Figs. I5, I6). Conversely, the non-touch technique of intermittent catheterisation proved most efficacious in the immediate and early stages, and in many cases, particularly in incomplete lesions, the bladder could be kept sterile throughout. Needless to say what beneficial effects this had on the future life of the paralysed. In a report on 370 traumatic paraplegics and tetraplegics, admitted immediately or early following injury and treated systematically with intermittent catheterisation over a period of 


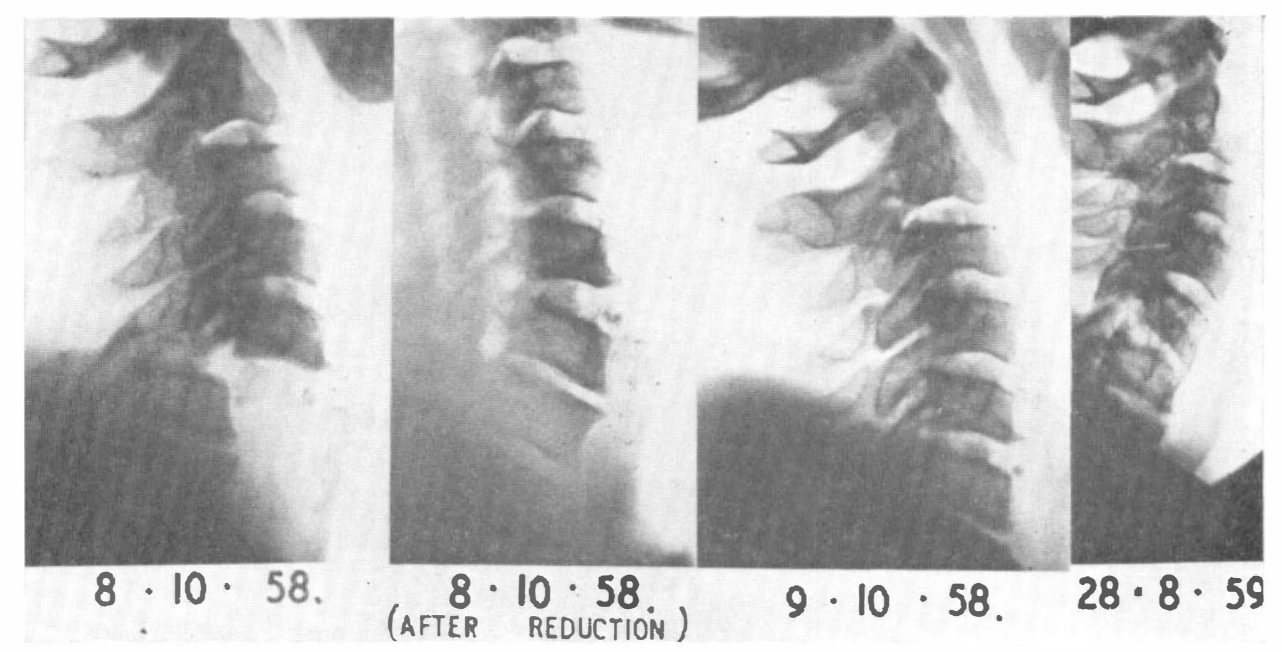

FIG. 7

Profound unstable retro-hyperflexion fracture dislocation of the 6th cervical vertebra. Note the fulcrum produced by the extreme narrowing of the processus spinosi. Following reduction and fixation by head traction.

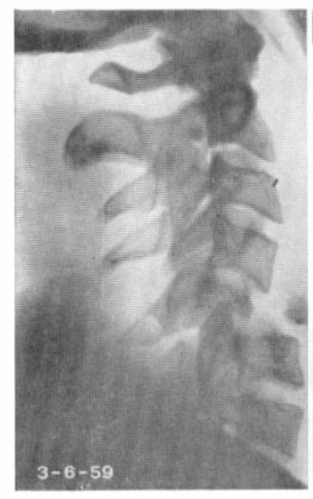

(a)

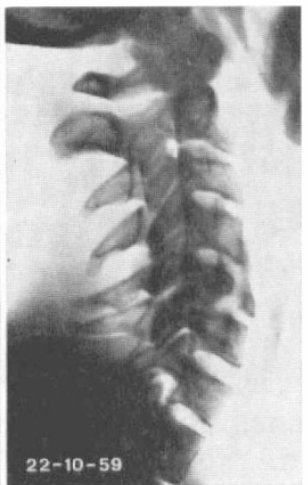

(b)

FIG. 8

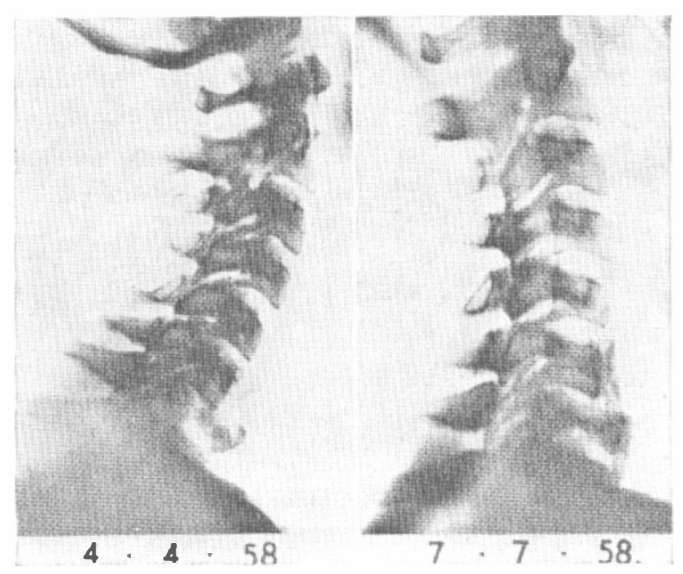

FIG. 9

FIG. 8.- (a) Profound unstable anterior hyperflexion fracture dislocation of 5 th cervical vertebra with rotation and locking facets. Note the separation of the processus spinosi. (b) Demonstrates the excellent reduction by head traction and anterior fusion by the natural forces of repair.

FIG. 9.-Burst fracture of 7 th cervical vertebra with anterior displacement of half of the broken vertebra. Reduction and fixation by natural anterior fusion. 


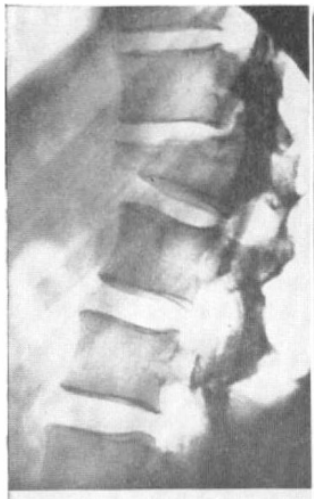

$24 \cdot 12 \cdot 54$

FIG. IO

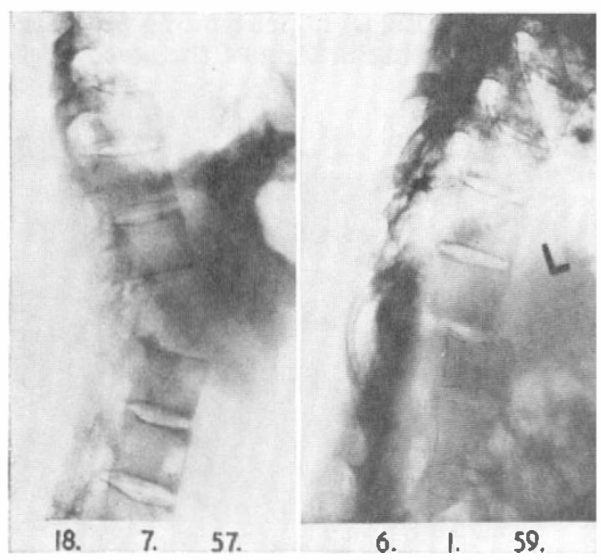

FIG. II

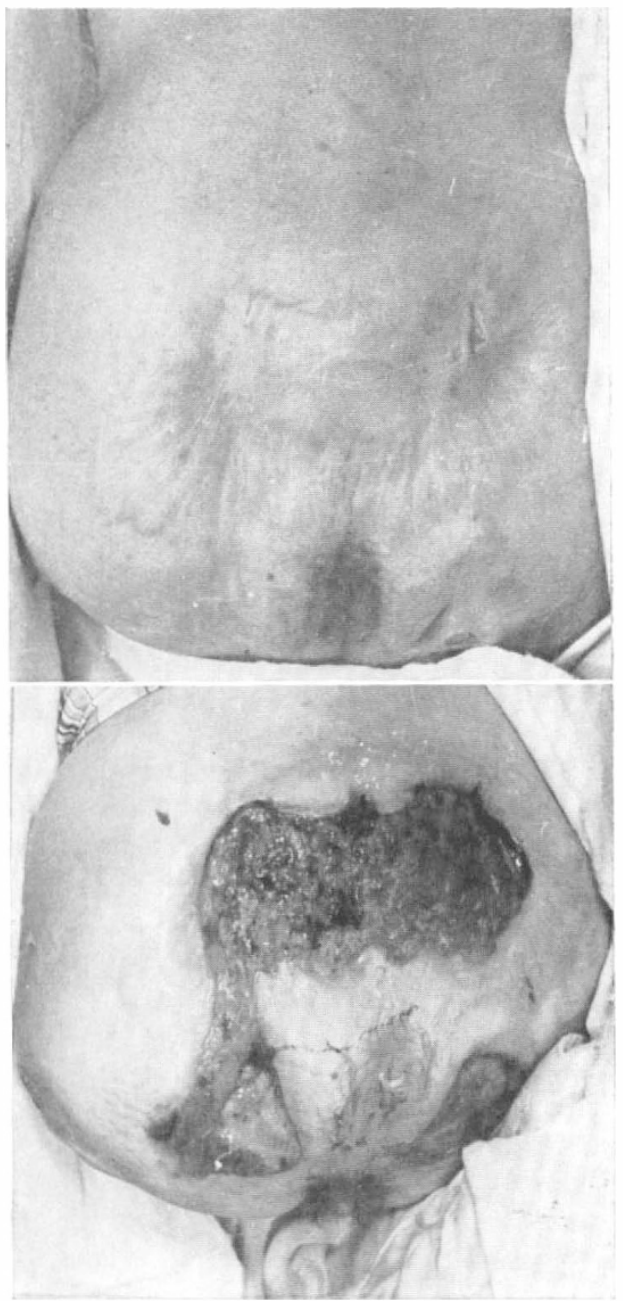

FIG. I2

FIG. I0.-Unstable fracture dislocation of I2th dorsal vertebra. Following reduction by conservative treatment (postural reduction).

FIG. I I.-Gross unstable retro-hyperflexion fracture of the thoracic spine with large gap through hyperextension in a case of ankylosing spondylitis. Reduction in flexion (postural reduction).

FIG. I2.-Deep necrotic sacral sore communicating with ischial sores. Healing by excision of slough and conservative treatment.

I I years, published in I966 (Guttmann and Frankel, I966) it could be shown that $296(62 \cdot 2$ per cent) had sterile bladders at the time of discharge from the Centre, and the incidence of bladder stones ( 0.6 per cent) and kidney stones ( $\mathrm{I} \cdot 7$ per cent) and ascending infection resulting in hydronephrosis $(7.4$ per cent) was profoundly diminished as compared with previous publications (Guttmann, I953). In particular, the dreaded complication of urinary fistula was virtually avoided. In 


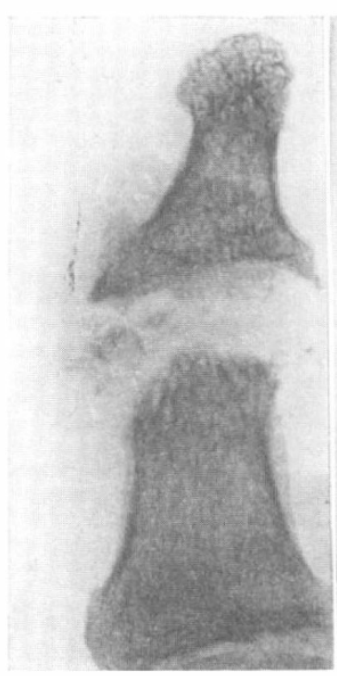

(a)

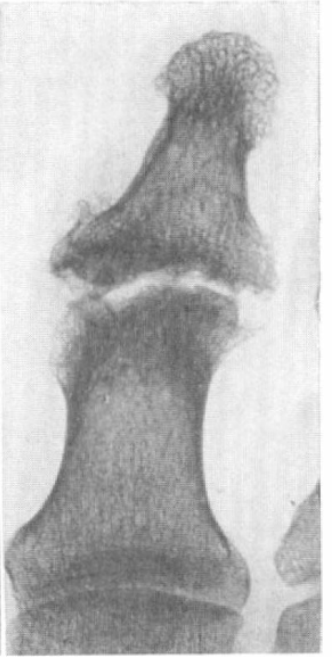

(b)

Fig. 13

(a) Complete disintegration of terminal joint of a big toe resulting from penetrating pressure sore. (b) Restoration of middle phalanx and joint following healing of the sore.

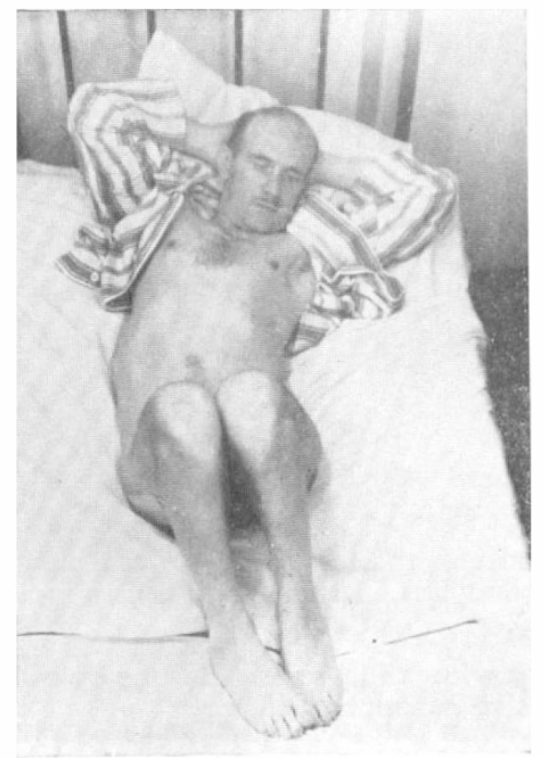

(a)

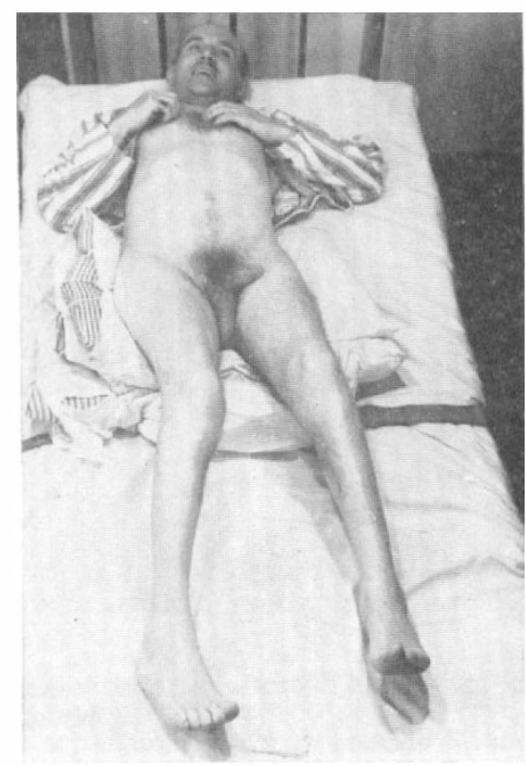

(b)

FIG. I4

(a) Profound flexion and adduction contractures due to intractable spasticity in a complete transverse lesion below T6. Two persons were necessary to abduct the legs for urethral catheterisation. (b) Elimination of spasticity and contractures following an intrathecal alcohol block. 


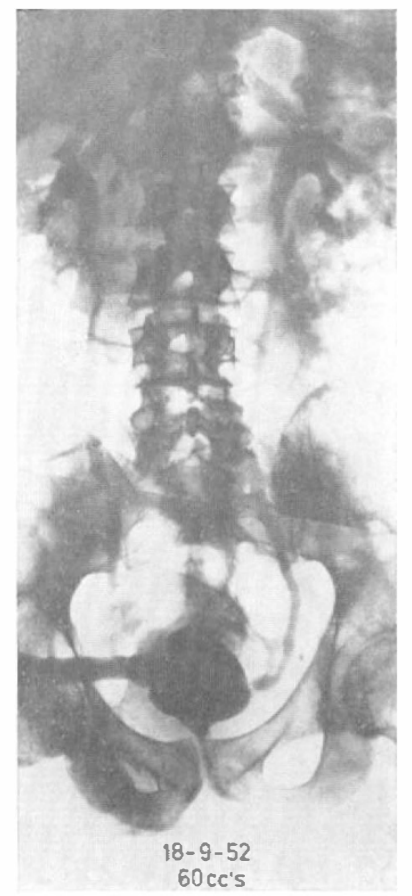

FIG. I 5

Paralysed contractured bladder following suprapubic cystotomy with bilateral reflux shown in cystogram.

spite of many thousands of intermittent urethral catheterisations performed in this large number of patients during the many years of study, there has not been a single case of urethral, penoscrotal or vesico-vaginal fistula. These remarkably good results have been confirmed by many workers in this field, amongst them Walsh (I968) who found 82.6 per cent sterility in 92 patients, Dollfus and Molé (I969), who found 82 per cent sterility in men and 67 per cent in women, Jacobson and Bors (I970), Pearman (I97I).

Last, but by no means least, it was quite revolutionary to teach and impress on the authorities of medical and social services, in particular the Ministries of Labour and Housing authorities, that the mere fact that a person was a paraplegic or tetraplegic did not justify care in one of the institutions for the incurable, but that rehabilitation to useful life and employment was possible. With this object in view, regular work and sport were introduced from the beginning as an essential part of the physical and psychological treatment of these patients which, in due course, proved so very successful in their total rehabilitation by counteracting the adverse psychological reactions which follow in the wake of this tragedy and restoring self-confidence, self-dignity, competitive spirit, sportsmanship and community spirit in most of these men and women.

As mentioned before, one of the great anxieties amongst paraplegics and tetraplegics was sexual impotence and infertility which, actually, was dogmatically accepted by most members of the medical profession and the public as a whole. Experience has shown that this concept is not correct, and certain paraplegics and 


\section{BRICE-IncornP.C.7. Comp.T.2. Injured 3. 4.58- - Examination 15.10.65.}

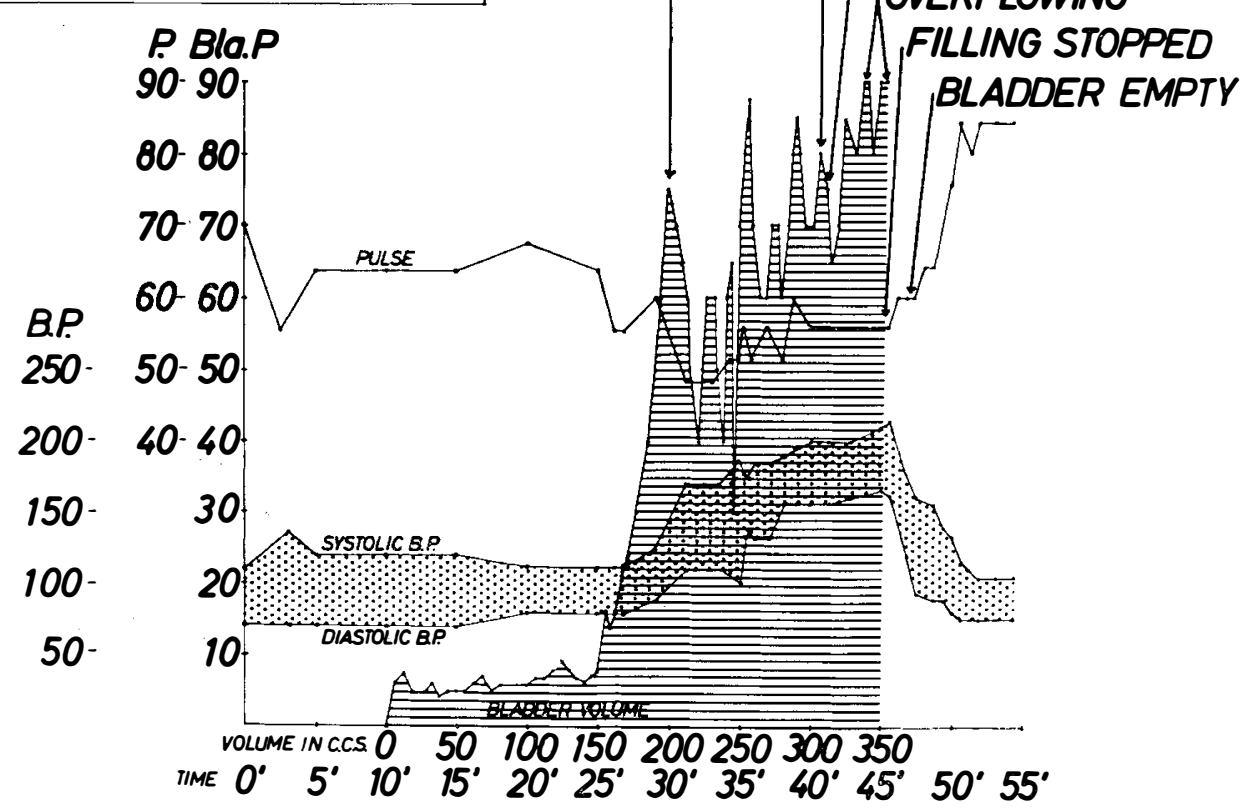

FIG. I6

Hyper-reflexia of autonomic and cardiovascular mechanisms following detrusor contraction of the bladder in a complete lesion below $\mathrm{T} 2$.

TABLE I

Children born of, or adopted by, paraplegic and tetraplegic parents

\begin{tabular}{lcc}
\hline & $\begin{array}{c}\text { Number of } \\
\text { parents }\end{array}$ & $\begin{array}{c}\text { Number of } \\
\text { children }\end{array}$ \\
\hline Own children & & \\
Paraplegic fathers & 96 & I88 \\
Paraplegic mothers & I5 & 2 I $^{1}$ \\
Tetraplegic fathers & I2 & I7 \\
Tetraplegic mothers & I & I \\
Totals & $\overline{\text { I24 }}$ & -227 \\
Adopted children & & 73 \\
Paraplegic fathers & 55 & 6 \\
Tetraplegic fathers & 4 & 79 \\
Totals & $\overline{59}$ &
\end{tabular}

${ }^{1}$ One illegitimate. 
TABLE II

Analysis of 3000 cases, of whom $65^{\circ} 4$ per cent are traumatic lesions, at the National Spinal Injuries Centre, Stoke Mandeville Hospital

\begin{tabular}{|c|c|c|c|c|}
\hline & $\begin{array}{c}\text { Servicemen } \\
\text { and pensioners }\end{array}$ & Civilians & Total & Percentage \\
\hline Traumatic lesions & 753 & 1210 & 1963 & $65 \cdot 4$ \\
\hline Transverse myelitis & 34 & 125 & 159 & $5 \cdot 3$ \\
\hline Poliomyelitis & 89 & 63 & 152 & $5 \cdot 1$ \\
\hline Vascular processes & II & 95 & 106 & $3 \cdot 5$ \\
\hline Spina bifida & - & 62 & 62 & $2 \cdot I$ \\
\hline Multiple sclerosis & $4 \mathrm{I}$ & 80 & I2I & $4 \cdot 0$ \\
\hline Disc lesions & 6 & 27 & 33 & $I \cdot I$ \\
\hline Miscellaneous & 66 & 338 & 401 & 13.5 \\
\hline Totals & 1000 & 2000 & 3000 & $100 \cdot 0$ \\
\hline
\end{tabular}

even tetraplegics can carry out intercourse in one way or another, have sired children and paraplegic and tetraplegic women have become pregnant and borne normal children (Table I).

Since the Centre was opened, over 6000 paraplegics and tetraplegics, the majority of them with traumatic lesions, have been admitted as in-patients to the Centre. In 1965 I published a statistic of my first 3000 patients, divided into exservice personnel and civilians. The majority of them, I963 $(65.4$ per cent) were traumatic lesions at that time and 23.6 per cent of them tetraplegics (Table II). It may be noted that the percentage of tetraplegics has greatly increased in the ensuing years, which is in accordance with the experience of other spinal units in various countries.

The death rate amongst the 3000 patients is given in Table III. This statistic includes every patient who died either during treatment in the Spinal Centre or after discharge home or to other institutions. The corrected figures show the death rate related to spinal injuries only and reveal the great difference in the death rate between the traumatic cases of the world wars and the corrected figure of civilians of 9 per cent and that of the armed forces admitted since 1946 of only $6 \cdot 4$ per cent. These figures demonstrate the dramatic change which has taken place in the prognosis of spinal cord injured men and women since the introduction of the new concept of management. Many of them are still alive well over 30 years later. It is clear, therefore, that today the problem of paraplegia and tetraplegia is no longer a medical problem alone. It has become a social problem of increasing importance from year to year. Table IV shows the domestic resettlement of these 3000 patients, which shows that the majority, 2059, were living either in bungalows or in their previous homes once their houses were adjusted to their disability by widening doors and toilets, providing ramps and garages, etc. This is, of course, the ideal solution of domestic resettlement for the spinal paralysed to live within the community. Table $\mathrm{V}$ gives an analysis of the employment statistics of 2012 paraplegics and tetraplegics available for employment at the time of the statistics. 54.5 per cent were employed full time in a great variety of jobs including professions such as I $7 / \mathrm{I}-\mathrm{H}$ 


\section{TABLE III}

Mortality statistics of the first 3000 patients of the National Spinal Injuries Centre, Stoke Mandeville Hospital (1944-63)

\begin{tabular}{|c|c|c|}
\hline & Total & Percentage \\
\hline \multicolumn{3}{|l|}{ Total material } \\
\hline Number of cases & 3000 & $100 \cdot 0$ \\
\hline Deaths & 496 & I6.5 \\
\hline Corrected figure & 343 & II 4 \\
\hline \multicolumn{3}{|l|}{ Traumatic patients } \\
\hline Number of cases & 1963 & $100 \cdot 0$ \\
\hline Deaths & $33 I$ & I6.9 \\
\hline Corrected figure & 242 & $12 \cdot 3$ \\
\hline \multicolumn{3}{|c|}{ Servicemen and pensioners } \\
\hline Number of cases & 753 & $100 \cdot 0$ \\
\hline Deaths & 180 & 23.9 \\
\hline Corrected figure & 132 & $17 \cdot 5$ \\
\hline \multicolumn{3}{|l|}{ Civilians } \\
\hline Number of cases & 1210 & $100 \cdot 0$ \\
\hline Deaths & I $5 \mathrm{I}$ & $12 \cdot 5$ \\
\hline Corrected figure & IIO & $9 \cdot 0$ \\
\hline \multicolumn{3}{|c|}{ Analysis of servicemen and pensioners } \\
\hline \multicolumn{3}{|c|}{ World War I } \\
\hline Number of cases & 67 & $100 \cdot 0$ \\
\hline Deaths & 39 & $58 \cdot 2$ \\
\hline Corrected figure & 15 & $22 \cdot 4$ \\
\hline \multicolumn{3}{|l|}{ World War II } \\
\hline Number of cases & 468 & $100 \cdot 0$ \\
\hline Deaths & I25 & $26 \cdot 7$ \\
\hline Corrected figure & I03 & $22 \cdot 0$ \\
\hline \multicolumn{3}{|c|}{ Post-war period (from I946) } \\
\hline Number of cases & 218 & $100 \cdot 0$ \\
\hline Deaths & I6 & $7 \cdot 3$ \\
\hline Corrected figure & I4 & $6 \cdot 4$ \\
\hline
\end{tabular}

\section{TABLE IV}

Domestic resettlement of 3000 patients

Living at home

Living in paraplegic settlements, hostels and homes for the disabled 2059

Patients under treatment at Stoke Mandeville Patients under treatment at other hospitals Deaths 


\section{TABLE V}

Employment statistics on 3000 patients

Number Percentage

I. Overall analysis

Deceased

496

Retired and over age

I03

Physically unfit (including 64 cervicals) I43

Under treatment at Stoke Mandeville $5 \mathrm{I}$

Under treatment at other hospitals 54

Not traced

Available for employment

Total

3000

2. Available for employment

Full-time employed

Part-time employed

Home occupations

Not working

\begin{tabular}{|c|}
\hline $\begin{array}{r}1718 \\
294\end{array}$ \\
\hline 294 \\
\hline 2012 \\
\hline
\end{tabular}

Total

Full-time

Home occupations

Total

teaching, law, accountancy, and medicine. Actually, several paralysed medical post graduates of Stoke Mandeville have become leaders of Spinal Units in certain countries and one of them is a professor at Harvard University. At least one example of medical men who have continued their profession after having become paraplegics may be described. This was an outstanding Hungarian paediatric surgeon who sustained a complete paraplegia below the IIth thoracic segment. I saw him 4 months after injury when he was still lying in bed and was not able to sit up. He was admitted to Stoke Mandeville and made an excellent rehabilitation. Following a lengthy discussion with him about his future, he reluctantly promised to take up surgery again. Figure I7 illustrates how he adapted himself to his surgery. He wrote to me 4 months after discharge from Stoke Mandeville: 'I am sending you photographs of my first major operation (megacolon). This coincided with my 59th birthday, indeed a very happy occasion.' 
Including II $\circ$ per cent of the statistic who did part-time work and I9.9 per cent engaged in home occupations, altogether I 7 I 8 ( $85^{\circ} 4$ per cent) were engaged in remunerative work as useful members of the community-and payers of income tax.

Paraplegics and tetraplegics have also become sportsmen and sportswomen in their own right as a result of their training at the Centre, and take part regularly in the Stoke Mandeville Games for the Paralysed which I founded in I 948 and which
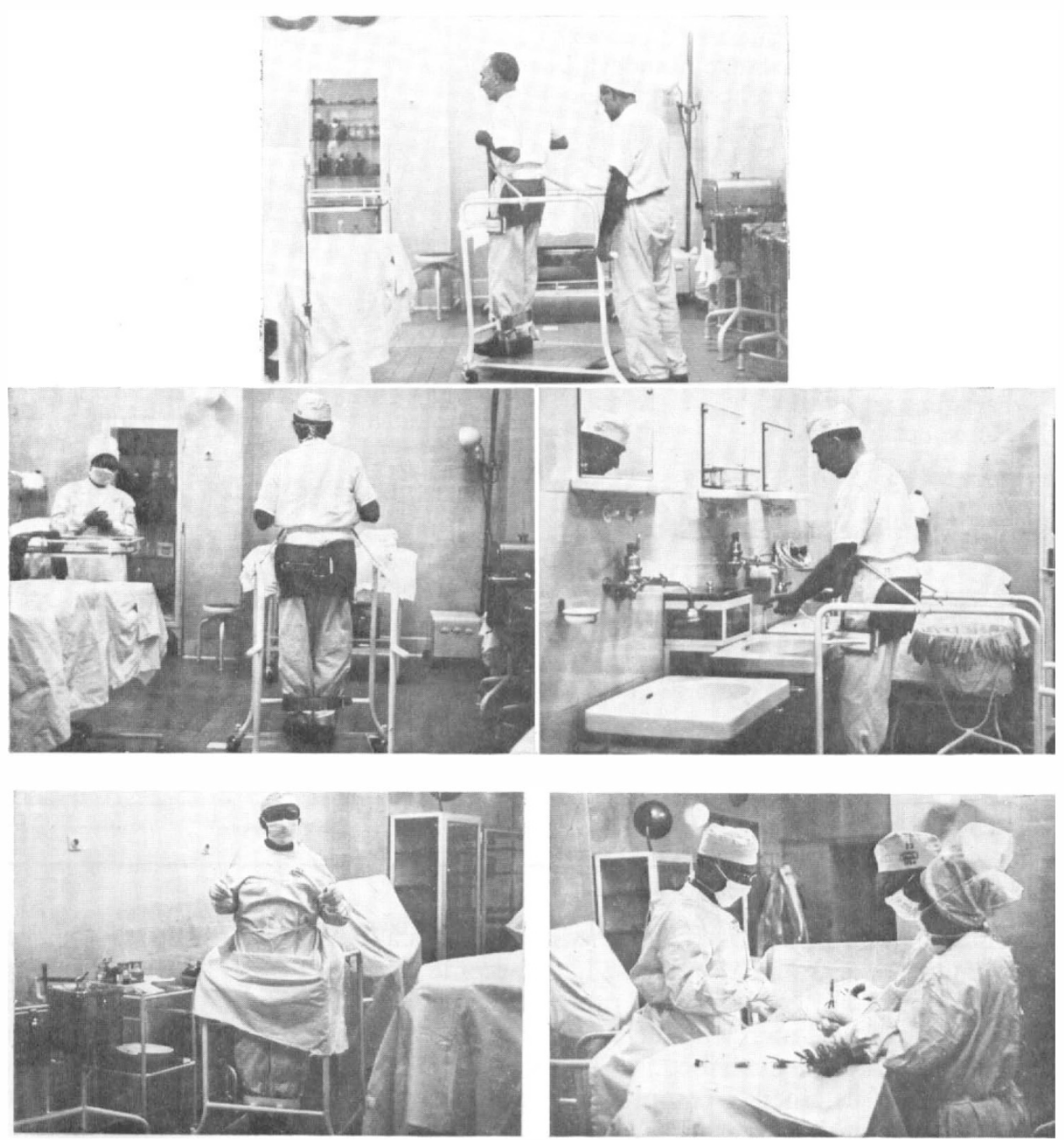

FIG. I7

Demonstrating return to surgery of a rehabilitated surgeon following fracture dislocation of the thoraco-lumbar vertebra. 


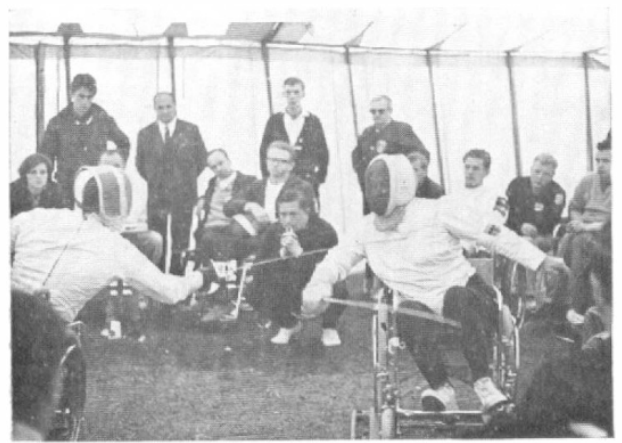

FIG. I8

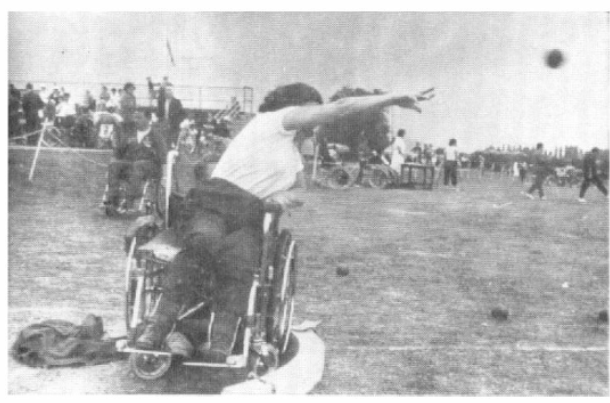

FIG. 20

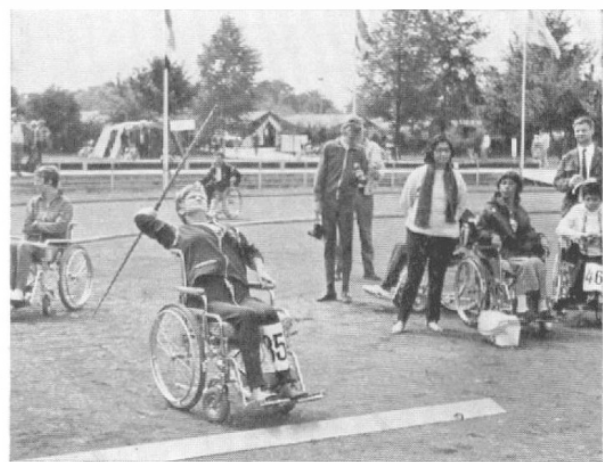

FIG. 19
FIG. 18.-Fencing competition.

FIG. 19.-Throwing the javelin.

FIG. 20.-Putting the shot.

have been for many years a world-wide sports movement, the Olympics for the Paralysed. In 1977, we will celebrate the 25th Jubilee of the International Stoke Mandeville Games. These Games are held every year at the end of July at Stoke Mandeville Sportsground and every fourth year, if possible, in the country of the Olympic Games-the first time in 1960 in Rome, the second (1964) in Tokyo, the third (1968) in Israel (as the organisers of the Olympics in Mexico were unable to stage our Games), the fourth (1972) in Heidelberg, where rooo paraplegic and tetraplegic wheelchair athletes representing 45 countries took part. This year (1976), these Games took place in Toronto, and for the first time not only I IOO paraplegics but 600 amputees and blind took part. Although our Toronto Olympiad, like the Olympic Games in Montreal, became victims of political interference because of the participation of our fully racially integrated South African member organisation, and teams of eight countries either did not attend or were forced by their governments to withdraw once they arrived, this political blackmail did not diminish the resounding success of the Toronto Games, thanks to the firm stand of the responsible Executive Committees of the International Stoke Mandeville Games Federation (I.S.M.G.F.) and the International Sports Organisation for Multi-disabled (I.S.O.D.) and above all the disabled athletes themselves. They remained loyal to our ideals 'Friendship, Unity and Sportsmanship' which reject political, racial and religious prejudices (Guttmann, 1976). Figs I8-23 show scenes from competitions.

As the result of the great success of this sports movement for the paralysed, I founded in 1960 the British Sports Association for Multi-disabled and in 1964 the International Sports Organisation for Multi-disabled was created. 


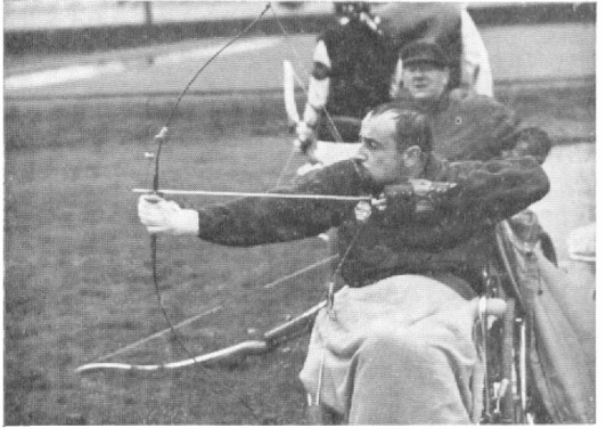

FIG. 2I

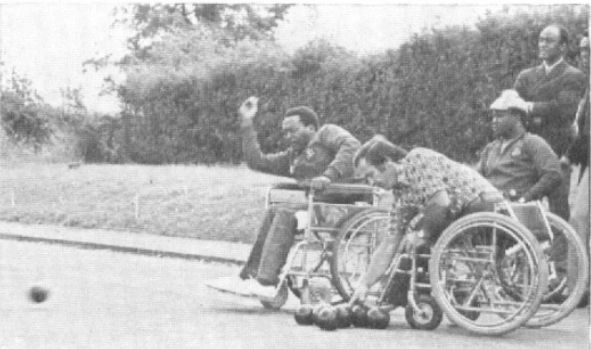

FIG. 22

FIG. 2I.-Archery contest of a complete tetraplegic below C6. Note the right hand is fixed on the bow as he has no active finger function and note the bow is pulled by a hook attached to the palm of the hand.

FIG. 22.-Bowling competition.

In 1968, the Stoke Mandeville Sports Stadium for the Paralysed and other Disabled, the first of its kind in the world, was built, which was opened by Her Majesty the Queen in 1969. Sports organisations of the able-bodied are taking an increasing interest in sport for the disabled and it was in 1956, during the Olympic Games in Melbourne, that the Olympic Committee awarded the Fearnley

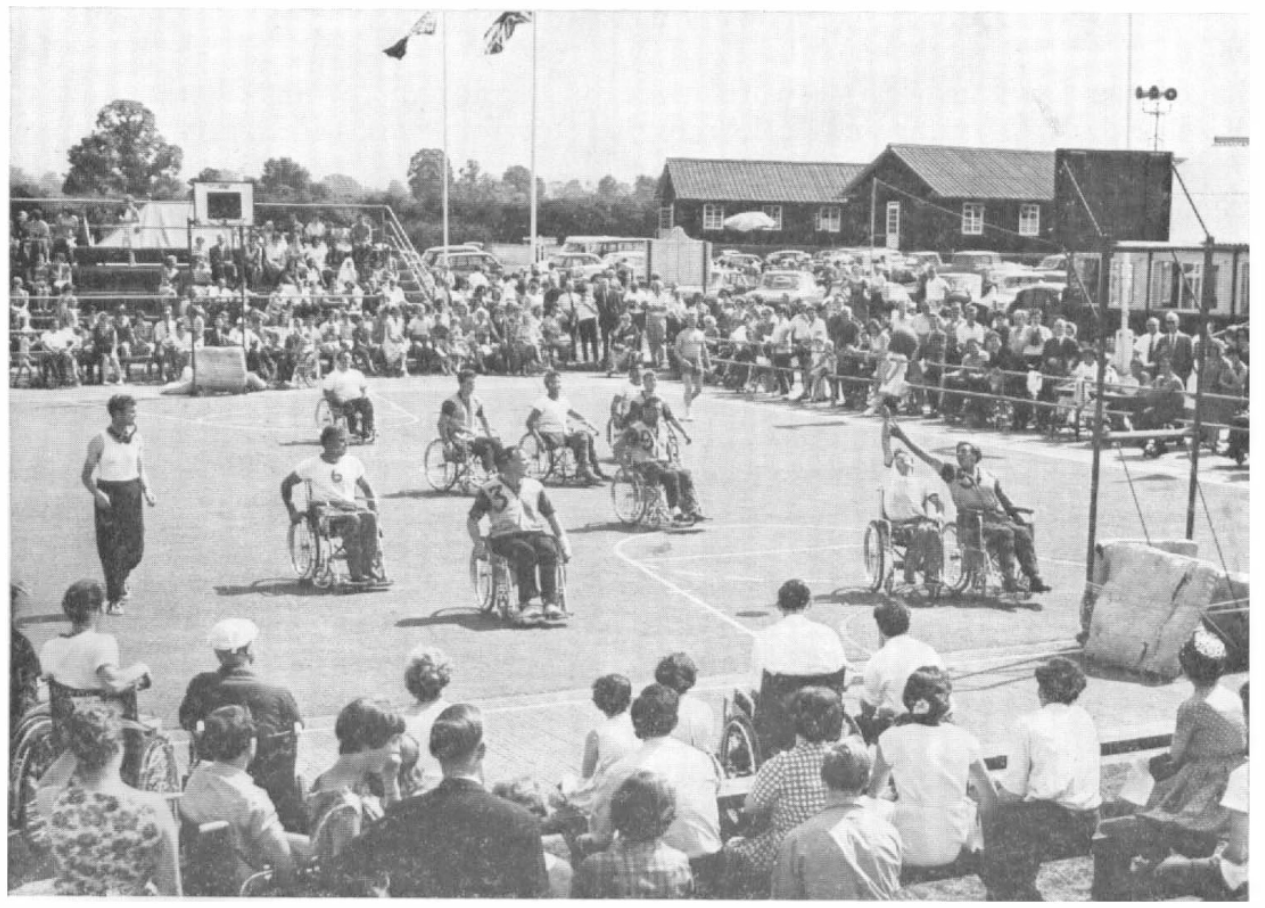

FIG. 23

Basketball match. 


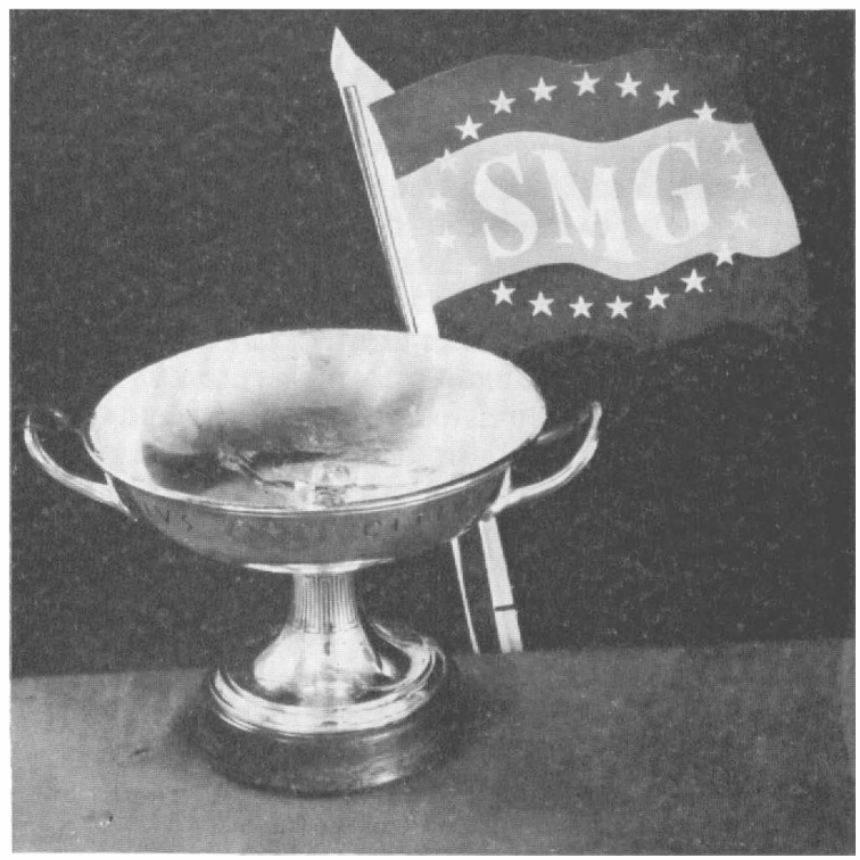

FIG. 24

The Fearnley Cup awarded to the Organisation of the International Stoke Mandeville Games by the International Olympic Committee during the Olympic Games in Melbourne, I956.

Cup to the Organisation of the Stoke Mandeville Games, an Olympic award which any sports organisation can win for outstanding achievement in the service of the Olympic ideals (Fig. 24).

\section{Late Health Deviation}

The now greatly increased lifespan of paraplegics as well as tetraplegics as the result of the modern principles of management has afforded the opportunity to observe late health deviations in the victims of spinal cord lesions. They can be divided into those related and those unrelated to the cord injury.

The group related to paraplegia include ascending neurological symptoms, mainly loss of pain and temperature sensibility in remote dermatomes of the body as a result of late myelopathy of vascular origin, resulting in cyst formation mainly in the posterior horns and to a lesser degree also in the posterior columns. However, the most common late health deviation is still chronic pyelonephropathy with or without amyloidosis as a result of ascending bladder infection and leading to cardiovascular complications including hypertension, eventually causing death. Moreover, obstruction at the bladder neck or external sphincter are also, as a rule, complications which may develop later but can be overcome by important operations-i.e., resection of the bladder neck (Emmett, I945) and/or resection of the external urethral sphincter (Cosbie-Ross, 1960) which have proved highly successful in restoring free urinary flow. There is no doubt that cancer of the bladder is one of the not-infrequent late complications of spinal paraplegia (Melzak, I966). 
Recurrences of pressure sores are also relatively common late complications, necessitating readmission to the Spinal Centre for conservative treatment or plastic repair. Amyloidosis due to osteomyelitis as a result of pressure sores affecting bone and joints may also be a late complication. However, cancerous degeneration of sores or scars was seen in very few cases only.

Recurrent lung complications in tetraplegia is not uncommon as late health deviation and a few tetraplegics died from this complication.

Fractures due to osteoporosis frequently caused by a minor injury, often called 'spontaneous' fractures, and para-articular ossifications are also causes of late complications as a result of spinal cord injuries.

Drug addiction and suicide related to paraplegia are very rare in this country.

The late health deviations unrelated to paraplegia and tetraplegia are not significantly different from those of the able-bodied. They include accidents, mainly road accidents, furthermore, cardiovascular changes, diabetes and cancer of lung, intestines and prostate (the latter very rare) and secondaries of lung cancer.

\section{Future Outlook}

What does the future hold for the clinical management and social reintegration of paraplegics and tetraplegicsin this country? Successful treatment and rehabilitation in spinal injuries centres is now well established for this multidisciplinary subject of medicine and surgery. However, are there enough spinal centres to cope with the ever-increasing number of both paraplegics and, in particular, tetraplegics? The answer is a clear 'No' as far as the South of England is concerned. When I retired from the Directorship of the National Spinal Injuries Centre, there were no less than 195 beds and in addition 30 beds in a hostel for those tetraplegics and severely handicapped paraplegics who, for various reasons, were not able to return home or where the families were no longer able to look after them at home. The number of clinical beds of the Centre has since been reduced to 156 for one reason or another, although the waiting list for new cases and readmission of former patients for check-ups or specialised treatment has not diminished-on the contrary is, in fact, still very large. This year 229 new injuries were admitted to Stoke Mandeville, about the same number of new patients as when the Unit had 195 beds. There are at present 40 new patients on the waiting list, among them II who, although acute injuries originally, could not be admitted. Moreover, 50 former patients are on the waiting list for readmission for check-ups or specialised treatment. It may be noted that some other units, such as Southport and Oswestry, have also not enough beds to readmit former patients for check-up or specialised treatment. The results of this sorry situation are only too obvious. In the first place any delay to give new cases, especially traumatic paraplegics as well as tetraplegics, a comprehensive specialised treatment from the start must necessarily revert to the bad old times when these unfortunate cases were admitted to Spinal Centres at later dates with the various serious complications mentioned before, necessitating prolonged in-patient treatment resulting not only in considerably increased cost, but also not infrequently, and most important, in irreversible damage to the organism caused by inadequate initial management elsewhere, in particular to the bladder and kidneys. In this respect a report in recent years published by Jacobson and Bors (1970) on the tragic results of delay in admitting spinal cord casaulties from the Vietnam combat speaks for itself and fully confirms, 
as many previous publications, my anxiety about the present situation still prevailing in this and other countries.

The other unfortunate result of the shortage of beds for a comprehensive service for spinal cord sufferers is that the treatment and rehabilitation has to be curtailed and patients may be discharged prematurely, i.e., physically more or less fit, but not psychologically and socially readjusted to cope with the new life in the world around them.

Today preventive medicine is generally accepted as the philosophy of the medical profession and the authorities concerned with the welfare of the people in the community. Alas-there is still a great need to apply this principle to men, women and children suffering from spinal cord paralysis and being confined to a wheelchair for the rest of their lives.

Since 1967 , negotiations have been held between the leaders of the spinal units and the authorities of the Department of Health, when the need to increase the number of spinal units was stressed. Moreover, the Tunbridge Report on Rehabilitation, realising this need, also recommended an increase of two additional spinal units. However, nothing has materialised so far. I feel very strongly that this long delay on the part of the authorities responsible for the remedy of this unfortunate situation has become indefensible.

Having regard to the increased importance of this complex subject of medicine and surgery and the experience gained through the work of the spinal centres, the lack of official recognition of this specialty of spinal paraplegia and tetraplegia as one in its own right is detrimental for the future development of this complex branch of medicine and surgery. For there cannot be any doubt that this branch of medicine and surgery has developed for some years de facto as a multidisciplinary specialty of its own. If this were to be recognised by the Department of Health, the Colleges of Physicians and Surgeons and the Universities, it would attract suitable, younger doctors and surgeons to take up this specialty as their life's work, as is the case in other specialties concerned with treatment and management of specific organs, such as chest surgery, ENT, ophthalmology, etc. Moreover, in my long medical career, I have witnessed the struggle of neurology, which was either part of general medicine or psychiatry, to be recognised as a specialty in itself. The same applies to neurosurgery and orthopaedic surgery which previously were part of general surgery. Through their specialisation these specialties have made great contributions to mankind. It is ironical that this country, where the modern concept of treatment and rehabilitation of spinal cord sufferers was founded and which is now recognised and copied all over the world, is sadly lagging behind others in this recognition. To give some examples: the famous Harvard University at Boston has appointed the director of the Spinal Injuries Centre at West Roxbury, himself a paraplegic, as Professor of Spinal Injury and Social Medicine, and in Heidelberg the director of the Spinal Injuries Centre set up within the Orthopaedic University Hospital has been appointed Professor Ordinarius-i.e., holder of a Chair in Rehabilitation. Similar situations exist in Belgium and Poland. Moreover, spinal injuries centres in Basle and Geneva (Switzerland), Perth, Sydney, Melbourne, Adelaide and Brisbane (Australia), furthermore Chicago (U.S.A.), and Toronto (Canada) are attached to University Hospitals.

What is the attitude today of the community as a whole towards the victims of spinal cord injuries and disease? There is no doubt that the public as a whole have become more aware of their responsibilities towards their disabled fellow men in wheelchairs. However, in spite of resolutions passed unanimously by the United Nations on the 'Rights of the Disabled' (1975) and in this country by the legislation 
of the Chronically Sick and Disabled Persons Act, the practical application of these charters of humanity still leaves much to be desired.

In the rapid changing pattern of life of the community, even the able-bodied have difficulty in adapting to innovations and changes in the hustle of daily community living. How much more difficult then for the severely disabled in wheelchairs, considering the existing architectural barriers in public buildings, museums, theatres, sports and leisure centres, exhibition buildings and even houses. The same applies to problems of transport. It is indeed most deplorable that in our modern times people in wheelchairs, when travelling by train, have still to travel in the guard's van along with goods and animals. I saw a film in Switzerland where two paraplegics had to travel in the guard's van in the company of a pig! Although great improvements have been made in adjusting houses by the building of ramps and hand-rails, the widening of doorways, adjusting toilets and bathrooms, etc., public buildings, such as libraries, post offices, banks, shops, etc., still all too often present insurmountable barriers to the severely disabled person, particularly one in a wheelchair. Recently, in many cities and towns, special shopping centres have been built for pedestrians only, to avoid the congestion of traffic, and here it is especially important that the disabled should have parking places in the closest proximity so that they can reach the shopping centres easily in their wheelchairs. In this connection, it is gratifying to note that an increasing number of towns in this and in other countries are making special provision for parking places and public toilets for wheelchair users and other severely disabled citizens.

We are, of course, aware that in the present difficult economic situation in Great Britain, where over a million people are unemployed, and where we are reminded daily of how poor we have become, there is the danger that the severely disabled will be left behind and fall again into the background. However, as long as civilisation and humanity remain the basic principles of community life, no country can be so poor that it cannot afford to give its severely disabled citizens their rightful place in society, the more so as thousands of spinal paralysed are today playing their part in contributing to the wealth of the nation by their work and paying income tax. To be able to do that they had to covercome seemingly insurmountable obstacles caused by one of the greatest catastrophes which can befall mankind.

\section{REFERENCES}

Cosbie-Ross J. (1960). Division of the external sphincter. In Handbuch der Neurologie, Vol. XII, 88-9I.

Cushing, H. (1927). The Medical Department, United States Army in World War I, Vol. Surgery II, part I, 757.

Dick, T.B. (1949). Rehabilitation in chronic paraplegia. MD thesis, Manchester University.

Dollfus, P. \& MolÉ, L. (1969). Intermittent catheterisation. Paraplegia, 7, 204-206.

EmMETT, J. L. (1945). Transurethral resection in treatment of true and pseudo cord bladder. F. Urol. 53, 545 .

Frankel, H., HANCOCK, D. \& Hyslop, J. et al. (1970). The value of postural reduction in the initial management of closed injuries with paraplegia and tetraplegia. Paraplegia, 7 , I79-I92.

Gowland, E. L. (I94I). Spinal Cord injuries. Br. Med.F. I, 8 I4.

GuttmanN, L. (1945). New hope for spinal cord sufferers. N.Y. Med. Times, 73, 318.

GutTMANN, L. (1946a). Postural reduction. Nursing Times, 42, 798.

Guttmann, L. (1946b). Rehabilitation of spinal cord injuries. Br. F. Phys. Med. 9, I30, 162.

GuttmanN, L. (1949). Management of paralysis. In 'Intermittent catheterisation'. $B r$. Surg. Pract. 6, 445. Butterworths, London. 
GutTMANN, L. (1953). Treatment and rehabilitation of patients suffering from spinal cord injuries. In Sir Z. Cope (ed.), Official Medical History of the Second World War, Vol. Surgery 422-516. HMSO, London.

Guttmann, L. (I955). The problem of treatment of pressure sores. Br. F. Plast. Surg. 7, 196-213.

Guttmann, L. (1973). Spinal Cord Injuries: Comprehensive Management and Research, Ist ed. Blackwell Scientific Publ., Oxford.

Guttmann, L. (1976). Spinal Cord Injuries: Comprehensive Management and Research, and ed. Blackwell Scientific Publ., Oxford.

Guttmann, L. (1976). Textbook of Sport for the Disabled. HM+M, Aylesbury.

GutTMANN, L. \& FRANKeL, H. (I966). The value of intermittent catheterisation in the early management of traumatic paraplegia and tetraplegia. Paraplegia, 4, 63-84.

Guttmann, L., Munro, A., Robinson, R. \& Walsh, J. (I963). Effects of tilting on the cardio-vascular responses on plasma catecholamine levels in spinal man. Paraplegia, $\mathbf{I}, \mathbf{I}$.

Guttman, L., Silver, J. \& WyndhaM, L. (1958). Thermoregulation in the spinal man. Br. F. Physiol. 142, 408-418.

Jacobson, S. A. \& BorS, E. (I970). Spinal cord injuries in Vietnamese combat. Paraplegia, 7, 263-28I.

Johnson, R. H. \& SPALDING, J. M. (I964). The effect of surface and central temperature on hand blood-flow in subjects with complete transection of the spinal cord. $B r . \mathcal{F}$. Physiol. I4-15.

Melzak, J. (I966). The incidence of bladder cancer in paraplegia. Paraplegia, 4, 85-96.

Pearman, J. W. (I97I). Prevention of urinary tract infection following spinal cord injury. Paraplegia, 9, 95.

WAGNER, W. \& STOLPER, P. (I898). Die Verletzungen der Wirbelsäule und des Rückenmark. Deutsche Chirurgie, 40, 279. Enke, Stuttgart.

Walsh, J. (I968). Results on intermittent catheterisation. Paraplegia, 6, 74. 